\title{
Loss and damage in the IPCC Fifth Assessment Report (Working Group II): a text-mining analysis
}

\author{
Kees van der Geest and Koko Warner \\ United Nations University Institute for Environment and Human Security, Bonn, Germany
}

\begin{abstract}
'Losses and damages' refer to impacts of climate change that have not been, or cannot be, avoided through mitigation and adaptation efforts. After the establishment of the Warsaw International Mechanism for Loss and Damage (WIM), Loss and Damage is now considered the third pillar - besides mitigation and adaptation - of climate action under the United Nations Framework Convention on Climate Change (UNFCCC). This paper studies what the Contribution of Working Group II to the Fifth Assessment Report of the Intergovernmental Panel on Climate Change (IPCC WGII AR5) has to say about this emerging topic. We use qualitative data analysis software (text mining) to assess which climatic stressors, impact sectors and regions the report primarily associates with losses and damages, and compare this with the focus areas of the WIM. The study reveals that IPCC WGII AR5 primarily associates losses and damages with extreme weather events and economic impacts, and treats it primarily as a future risk. Present-day losses and damages from slow-onset processes and non-economic losses receive much less attention. Also, surprisingly, AR5 has more to say about losses and damages in high-income regions than in regions that are most at risk, such as small island states and least developed countries. The paper concludes with recommendations to the IPCC for its 6th Assessment Report (AR6) to include more evidence on losses and damages from slow-onset processes, non-economic losses and damages and losses and damages in vulnerable countries.
\end{abstract}

Key policy insights

- IPCC WGII AR5 discusses evidence about losses and damages predominantly in relation to sudden-onset disasters and economic costs.

- More research is needed on losses and damages from slow-onset processes and non-economic loss and damage, particularly in vulnerable countries in the Global South.

- Funding agencies should support research in these areas and IPCC WGII AR6 should pay more attention to these topics.

- Losses and damages are not only a future risk, but already a present-day reality for vulnerable people in climate hotspots. People-centred research by social scientists is crucial for enhancing understanding of what losses and damages mean in the real world.

\section{ARTICLE HISTORY}

Received 8 February 2019

Accepted 11 December 2019

\section{KEYWORDS}

Loss and damage; climate change; impacts; adaptation limits and constraints; vulnerability; IPCC

\section{Introduction}

Loss and Damage is an emerging concept in the climate change negotiations, as well as in research, policy and implementation of climate change action, and is expected to grow in importance in the coming years (Mechler et al., 2019). Losses and damages refer to impacts of climate-related stressors that have not been, or cannot be, avoided through mitigation and adaptation efforts (Warner \& van der Geest, 2013). Enhanced efforts to cut

CONTACT Kees van der Geest geest@ehs.unu.edu United Nations University Institute for Environment and Human Security, Platz der Vereinten Nationen 1, Bonn 53113, Germany

This article has been republished with minor changes. These changes do not impact the academic content of the article.

๑) 2019 Informa UK Limited, trading as Taylor \& Francis Group 
greenhouse gas (GHG) emissions, and effective adaptation and risk reduction measures, can reduce future losses and damages, but some losses and damages are unavoidable (Huq, Roberts, \& Fenton, 2013; Roberts, van der Geest, Warner, \& Andrei, 2014; van der Geest \& Warner, 2015). Some studies distinguish explicitly between losses - impacts that are permanent - and damages - impacts that are reversible (Doelle \& Seck, 2019; McNamara \& Jackson, 2019; Tschakert, Ellis, Anderson, Kelly, \& Obeng, 2019). However, in the climate negotiations and in the emerging literature on losses and damages, the term is usually is treated as one single concept (Fankhauser, Dietz, \& Gradwell, 2014). Following Byrnes and Surminski (2019), we use the plural form and lower case letters - losses and damages - to refer to impacts beyond or despite adaptation, and the upper case singular form - Loss and Damage - to refer to the associated policy debate.

Efforts to reduce GHG emissions have been insufficient so far, putting the world on a trajectory towards a strong increase in global temperature and associated changes in weather patterns, including precipitation and heat extremes, with high risks for human development (Meinshausen et al., 2009; van Vliet et al., 2012; Schellnhuber et al., 2012). Support for adaptation and risk reduction, particularly in developing countries that are most vulnerable to climate change impacts, has increased over the past decade, but vast adaptation deficits still exist (Burton, 2009). There is a growing consensus that there are constraints and limits to adaptation and the ability to avoid losses and damages (Dow et al., 2013; Preston, Dow, \& Berkhout, 2013; Warner, van der Geest, \& Kreft, 2013). This was recognized in the Summary for Policy Makers (SPM) of the contribution of Working Group II to the Fifth Assessment Report of the Intergovernmental Panel on Climate Change (IPCC) (henceforth referred to as WGII AR5), which states: 'Under all assessed scenarios for adaptation and mitigation, some risk from adverse impacts remain (very high confidence)' (IPCC, 2014, Summary for Policy Makers, p. 14).

WGII AR5 has, for the first time in an IPCC report, a chapter on adaptation opportunities, limits and constraints (Chapter 16). This chapter is an important input to the Loss and Damage debate, as it focuses on situations in which mitigation and adaptation efforts are not enough to avoid impacts from climate change (Nalau \& Leal Filho, 2018). The chapter was added after it was realized in the Fourth Assessment Report (IPCC, 2007) that this had become a reality. The chapter documents existing evidence on factors that make it harder to plan and implement adaptation (constraints) and the points at which actors' objectives cannot be protected from intolerable risks through adaptive actions (limits). When actors face 'hard limits', such adaptive actions are simply not possible. In the case of soft limits, options are currently not available (IPCC, 2014).

When actors experience constraints to adaptation, future losses and damages can be avoided, or at least reduced, by addressing these constraints. By contrast, when actors face hard adaptation limits, losses and damages are unavoidable. Besides avoidable and unavoidable, there is a third category, namely unavoided losses and damages (Verheyen \& Roderick, 2008). This last category moves the concept from an unsecure future to the present-day realities of vulnerable people. While questions remain about the degree to which losses and damages from extreme weather events can be attributed to global warming (Bouwer, 2011; Huggel, Stone, Auffhammer, \& Hansen, 2013; Hulme, 2014; James et al., 2014), it is increasingly clear that climate-related stressors have the potential to cause havoc among populations whose underlying vulnerabilities are not sufficiently addressed by adaptation and risk reduction policy (Roberts \& Pelling, 2019).

The concept of Loss and Damage first emerged in the climate negotiations in the early 1990s, when the Alliance of Small Island States (AOSIS) called for an insurance pool to compensate low-lying developing countries for the losses and damages caused by sea level rise. After this, it took more than two decades before the concept was institutionalized under the UNFCCC (Calliari, Surminski, \& Mysiak, 2019). This happened at the 19th Conference of the Parties (COP 19) in 2013 with the establishment of the Warsaw International Mechanism for Loss and Damage associated with Climate Change Impacts (WIM). UNFCCC decision 2/CP.19 to establish the WIM acknowledges that losses and damages can be reduced by adaptation and risk management strategies. However, it also recognizes that losses and damages sometimes involve more than what can be adapted to, or in other words, that some losses and damages cannot be avoided (UNFCCC, 2013a).

The objective of the WIM is to address Loss and Damage associated with impacts of climate change, including extreme events and slow onset events in developing countries that are particularly vulnerable to the adverse effects of climate change. It has three functions: (i) Enhancing knowledge and understanding; (ii) strengthening dialogue, coordination, coherence and synergies among stakeholders; and (iii) enhancing action and support, including finance, technology and capacity building (UNFCCC, 2013a). 
The WIM has an Executive Committee (ExCom) that meets approximately twice a year. The initial 2-year work plan of the WIM ExCom included nine activity areas. In 2017, at COP 23, the new 5-year workplan was approved. It included a smaller set of work streams that looked at slow onset events, non-economic losses, comprehensive risk management, migration and displacement, and action and support.

While the debate on climate change and Loss and Damage under the UNFCCC and the WIM has been largely political (Calliari et al., 2019), there is also a strong connection with the scientific community, and particularly with the IPCC. The IPCC plays an important role in the climate change negotiations as a provider of policy relevant information, involving government participation at different stages. Roberts and Huq (2015) show how important milestones in the climate negotiations have followed the presentation of more robust evidence on climate impacts and adaptation barriers in the assessment reports that the IPCC has published since 1990. The IPCC only assesses the existing literature on climate change, and does not conduct its own research. Therefore, knowledge gaps in the IPCC reports mostly reflect gaps in the literature.

The aim of this paper is to analyze how the terms 'loss' and 'damage' are used in IPCC WGII AR5. Through this analysis, the authors try to identify knowledge gaps in the report and areas that require attention from IPCC authors while they work on the Sixth Assessment Report (AR6), which is expected in 2021. The paper analyses which climatic stressors, impact sectors and regions WGII AR5 primarily associates with losses and damages, and tries to find out whether the report treats losses and damages primarily in connection to natural or human systems. For losses and damages to human systems, the paper looks at the relative attention given to economic and non-economic losses and damages.

The structure of the paper is as follows. First, we explain the methods used to analyse the more than 2500 pages ${ }^{1}$ of the report (data mining with qualitative data analysis software). After that, the results and discussion section analyses the use of the terms loss(es) and damage(s) by chapter, and by studying the words used in one sentence with the terms loss(es) and damage(s) along four axes of thematic interest: type of climatic stressors, impact on natural and human systems, economic and non-economic losses and geographic region. The last section provides conclusions with implications for the WIM and AR6.

\section{Materials and methods}

Qualitative data analysis software (QDA Miner/WordStat) was used to extract sentences from the 30 IPCC WGII AR5 chapters plus the SPM and the Technical Summary (TS) containing the words loss(es), lost, losing, lose, loser (s), damage(s), damaged or damaging. The resulting 1,911 sentences were exported to a spreadsheet and screened for technical and formatting issues (e.g. incomplete sentences, more than one sentence, text in tables not correctly exported, illegible symbols, erroneous spaces, page breaks) and to check whether the words loss and damage were actually used in a meaningful way (e.g. author name: 'Scott R. Loss' was excluded).

The resulting document contained 1,886 sentences, in which loss, damage and related words occurred 2,177 times (in some sentences, the words occurred more than once). Losses were mentioned much more often than damages (see Table 1). Table 1 also compares the use of the words loss/damage in AR5 with the previous fourth

Table 1. Use of the words loss and damage in AR4 and AR5.

\begin{tabular}{lcc}
\hline Key term & Frequency WGII AR4 & Frequency WGII AR5 \\
\hline Loss & 446 & 872 \\
Losses & 265 & 525 \\
Damage & 307 & 419 \\
Damages & 156 & 172 \\
Lost & 60 & 70 \\
Damaging & 19 & 42 \\
Lose & 27 & 23 \\
Damaged & 23 & 22 \\
Loser(s) & 7 & 18 \\
Losing & 8 & 14 \\
Total & 1313 & 2177 \\
\hline
\end{tabular}

Source: Authors. 
assessment report (AR4), published in 2007. It shows that both terms were used much more frequently in WGII AR5 than in AR4 WGIl. The set of 1,886 sentences was first used for a simple analysis of the frequency of occurrence of the words loss/damage, followed by a more in-depth analysis of how losses and damages feature in the report.

In the second step, the file with 1,886 sentences was subjected to analysis to explore the words most often used in combination with loss/damage. A threshold was set at frequency 10, meaning that words that cooccurred with loss/damage less than 10 times were excluded from the analysis. The QDA software automatically excludes words that convey little intrinsic meaning, such as about, above, according, across, etc. The resulting list contained 587 words used in relation to loss/damage. This list was cleaned by:

- Removing author names;

- Removing words that conveyed no intrinsic meaning in this context, but were not automatically excluded by the QDA software (e.g. chapter, section, common, IPCC, SPM, terms, important, related, report, role, similarly, etc.);

- Clustering words with the same root (e.g. agriculture and agricultural). We were conservative in clustering words because sometimes words with the same root have a different meaning (e.g. effects and effective were kept separate, and so were developing and developed). In case of doubt, the original text was consulted to verify whether words conveyed the same meaning.

- In a few instances, words were combined (e.g. the word Zealand only occurred in New Zealand; sheet only in ice sheet, greenhouse only in greenhouse gas, etc.). When the other word (e.g. ice in ice sheet, sea in sea level rise) also occurred independently, the frequency score was adjusted (i.e. frequency of ice sheet deducted from frequency of ice).

The cleaned word list contained 301 words that occurred at least 10 times in the same sentence with the words loss(es) or damage(s). This list and the frequencies with which the words occurred was used to support the analysis of how WGIl AR5 covers current and future losses and damages associated with impacts of climate change.

\section{Limitations}

The approach in this paper has several limitations. First, it covers only the contribution of WGIl. The reason to limit the scope was made because the contributions of Working Groups I and III focus on the causes of climate change and options for reducing GHG emissions respectively, and not on the impacts of climate change. The use of QDA software to count frequencies with which the terms loss and damage appear in chapters and to analyse which words are used most frequently in combination with these terms, proved an effective method for analysing the more than 2,500 pages of the report. However, and this is the second limitation, the results of this analysis do not necessarily provide a full understanding of what WGII AR5 has to say about loss and damage. To address this limitation, the original text was frequently consulted to be able to provide background, interpretation and a more profound and qualitative understanding to the more quantitative findings. A third limitation of the QDA analysis is that it does not capture all instances in which WGII AR5 discusses evidence on losses and damages. For instance, the report often writes about the adverse consequences of climate change that are 'beyond adaptation' (Botzen et al., 2019) as regular climatic impacts without using the words 'loss' or 'damage'.

\section{Results and discussion}

\section{Loss and damage by WGII AR5 chapter}

In this section, we look at how often different chapters use the words loss and damage (see Figure 1). The analysis is a simple frequency score, distinguishing loss (including related words, such as losses, lost and losing) and damage (including related words, such as damages, damaging and damaged). 


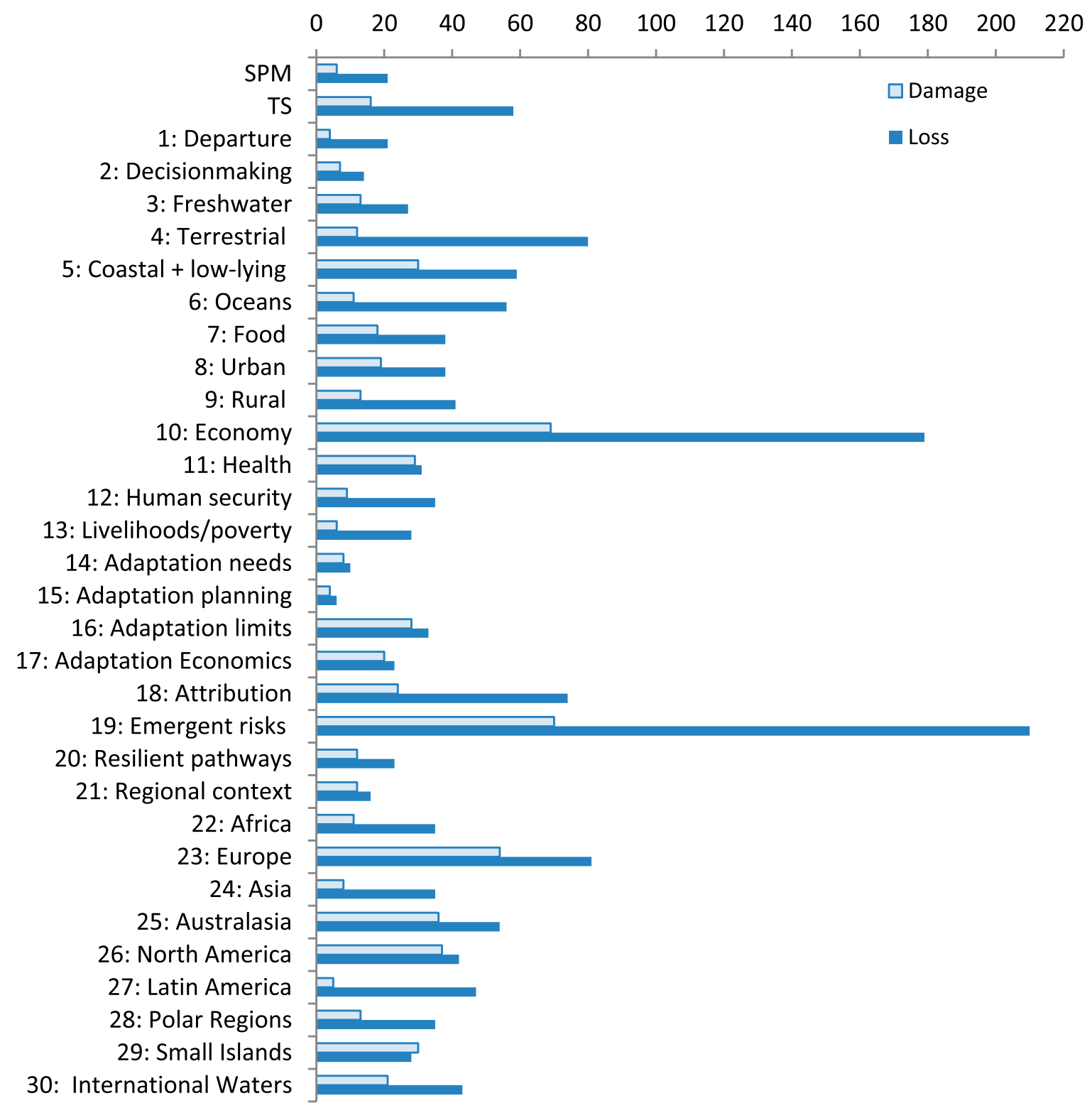

Figure 1. Occurrence of the words loss and damage by chapter. Source: Authors. The words included in the analysis are loss(es), lost, loser(s), losing, damage(s), damaged or damaging.

A first observation from Figure 1 is that the word 'loss' is used much more often than the word 'damage'. While some studies (e.g. Doelle \& Seck, 2019; McNamara \& Jackson, 2019; Tschakert et al., 2019) assign specific meanings to the words 'loss' (permanent impacts) and 'damage' (reversible impacts), it would be inaccurate to conclude that the adverse effects of climate-related stressors, reported in WGII AR5, tend to be irreversible. For example, when adverse effects of climate change on livelihood security are discussed, the authors usually speak of 'loss of livelihood' without implying that livelihoods are lost forever.

The words loss and damage are most frequently used in Chapter 19 (Emergent risks and key vulnerabilities) and Chapter 10 (Key economic sectors and services). This is an indication that losses and damages are mostly framed in economic terms and that they are primarily seen as future threats. While Chapter 10 states that the influence of climate change on the global economy is relatively small compared to other drivers, it does 
highlight more severe impacts in some countries. It states: 'Climate could be one of the causes why some countries are trapped in poverty, and climate change may make it harder to escape poverty' (IPCC, 2014, p. 663) According to Chapter 19, a severe risk of climate change for human systems is the loss of ecosystem services, which is often exacerbated by local human activities, including mitigation action, such as the production of bioenergy crops. According to Chapter 19, 'the risk of severe harm and loss due to climate change-related hazards and various vulnerabilities is particularly high in large urban and rural areas in low-lying coastal zones' (IPCC, 2014, p. 1042). Such areas are exposed to multiple hazards, such as sea level rise, storm surge, coastal erosion, saline intrusion and flooding. Key risks identified in Chapter 19 include food insecurity, loss of rural livelihoods caused by water scarcity and loss of coastal livelihoods due to sea level rise and acidification.

The lowest frequencies are in Chapter 15 (Adaptation planning and implementation), Chapter 14 (Adaptation needs and options) and Chapter 2 (Foundations for decision making). This is an indication that policy to address loss and damage is still in its infancy. A key message of Chapter 15 is that adaptation planning is improving but more complex than many assume. The chapter highlights an important gap in adaptation planning, namely that monitoring and evaluation of adaptation plans is inadequate, and that this needs to be systematized to know what actions are most efficient to reduce future losses and damages. Another key message of Chapter 15 involves the need to remove institutional barriers to effective adaptation planning. Chapter 14 notes a gap between adaptation needs and options to meet those needs - the adaptation deficit - and sees a role for 'procedures to deal with loss and damage' to fill this gap (Chapter 14, p. 845).

The terms loss and damage are used more often in the chapters on Europe, North America and Australia than in chapters on Asia, Africa, Latin America and Small Islands. This is surprising, because losses and damages are mostly associated with vulnerable countries such as small island developing states (SIDS) and least developed countries (LDCs).

Another observation from Figure 1 is that the words loss and damage are used substantially less often in the SPM (27 times in 44 pages) than in the Technical Summary (74 times in 76 pages). An explanation could be that the SPM needs to be approved line by line by member country governments, and that industrialized countries successfully minimized the use of the term, fearing that the rise of the concept would open the door to compensation claims. A summary of the approval session (38th session of the IPCC, 25-29 March 2014) shows that attempts by vulnerable countries to include loss and damage language in the text were resisted by industrialized countries (IISD, 2014).

\section{Terms associated with loss and damage: an analysis along 4 axes}

In this section, we look at the words used in combination with the terms loss and damage. First, all words are taken together, and illustrated visually in a tag cloud (see Figure 2). After that, the words are analysed along four axes: type of climatic stressors, impact on natural and human systems, economic and non-economic losses and geographic region.

Figure 2 shows a tag cloud of words that co-occurred at least 25 times in the same sentence with the words loss or damage in the 30 chapters plus the SPM and TS. The larger the word size, the more often mentioned in relation to loss/damage.

The word most often used in connection to loss and damage is 'risk' ( 383 times). This is an indication that the report talks about losses and damages mostly - but not exclusively - as a future threat. This is also in line with the analysis in the previous section, which showed that the words loss and damage most often occur in Chapter 19, which focuses on emergent risks and key vulnerabilities.

Other words used at least 100 times in combination with loss or damage were - in descending order - economic, impacts, flood, coastal, adaptation, ecosystems, events, species, insurance, water, sea, ice, costs, coral, infrastructure, biodiversity and land. The word 'events' is mostly used in 'extreme weather events'. By contrast, 'slow-onset events' were mentioned only once in relation to loss and damage.

The words in Figure 2 refer to climatic stressors, impact types, processes and potential solutions. Below, they are analysed in more detail, and in relation to other words. The use of the word 'adaptation' in one sentence with loss/damage is particularly frequent in Chapter 16. The central argument in that chapter is that there are limits 


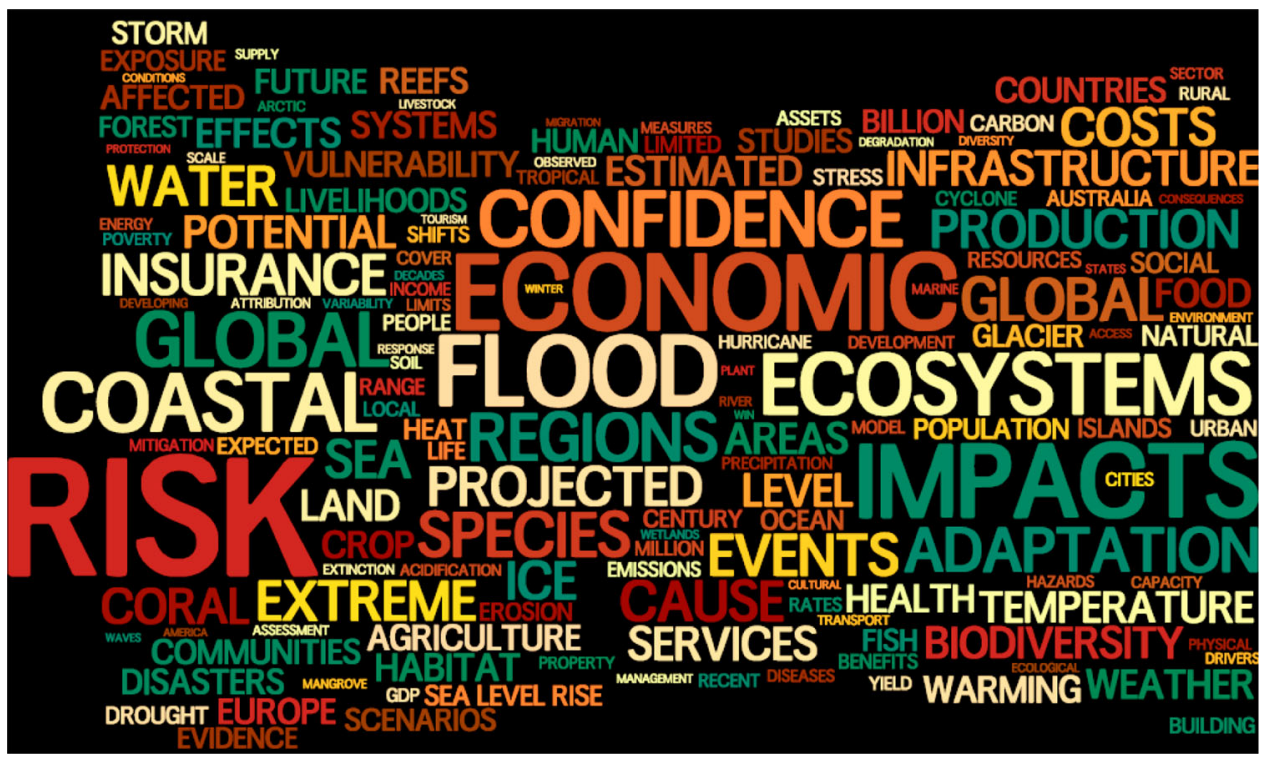

Figure 2. Tag cloud - Words used in one sentence with loss or damage. Source: Authors.

Notes: The threshold for inclusion in the figure was set at 25.

and constraints to adaptation (see also Dow et al., 2013) and that not all climate-related losses and damages can be avoided, even if mitigation and adaptation efforts are intensified.

\section{Type of climatic stressor}

Figure 3 shows the climatic stressors that are mentioned in WGII AR5 at least 10 times in one sentence with loss or damage. Floods clearly stand out as the climate-related stressor that is most frequently associated with losses

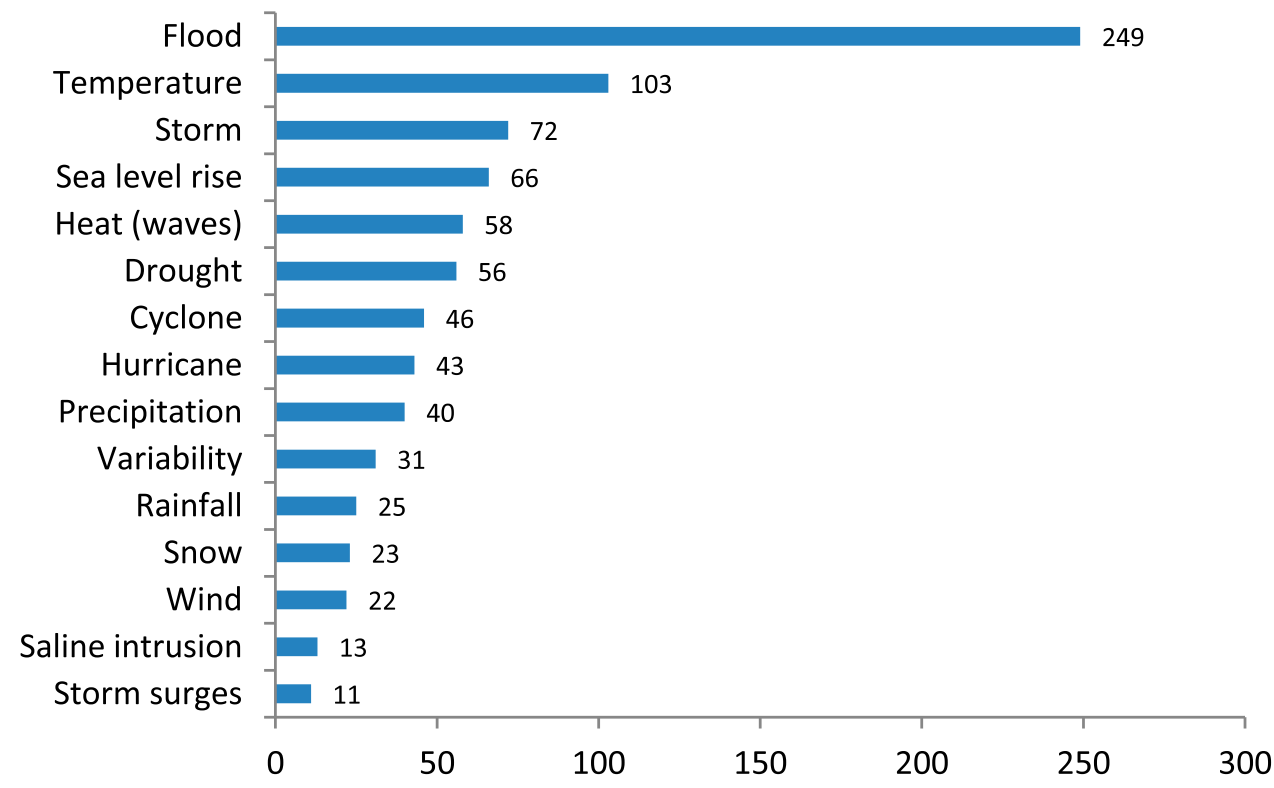

Figure 3. Type of climate-related stressor. Source: Authors.

Note: The threshold for inclusion in the figure was set at 10 . 
and damages. Second comes temperature (rise), which primarily causes losses and damages to ecosystems and animal and plant species. WGIl AR5 discusses evidence of losses and damages from extreme weather events, such as floods, storms, heatwaves and cyclones/hurricanes, more frequently than evidence of losses and damages from more gradual and slow-onset processes, such as sea level rise and changing rainfall patters. While there is a long tradition of documenting losses from sudden-onset disasters, and these are well-documented in WGII AR5, the report cited much less work on losses and damages from incremental climatic changes.

Interestingly, from a climate science perspective, it is less complicated to attribute losses and damages to anthropogenic global warming in the case of slow-onset processes than in the case of extreme weather events (James et al., 2014). However, assessing losses and damages from those slow-onset processes tends to be more difficult (James et al., 2019). A complicating factor is that slow-onset processes and sudden-onset events usually interact. For example, sea level rise (slow-onset) exacerbates impacts of cyclones and tidal floods (sudden-onset). Also, sudden-onset events can act as triggers to push slower-onset changes over tipping points (van der Geest \& Schindler, 2017). For example, a severe drought can trigger desertification. Another complicating factor in assessing losses and damages from slow-onset changes is that human systems have more time to adapt to these changes. Whereas an assessment of losses and damages from a cyclone would typically take place at a discrete point in time - usually soon after the cyclone - the timing of an assessment of losses and damages from sea level rise is less obvious.

\section{Impacts on natural and human systems}

Figure 4 shows words used in the same sentence as loss/damage that involve impacts on natural (the light blue bars) and human (the dark blue bars) systems. In some cases, a word can imply human impacts as well

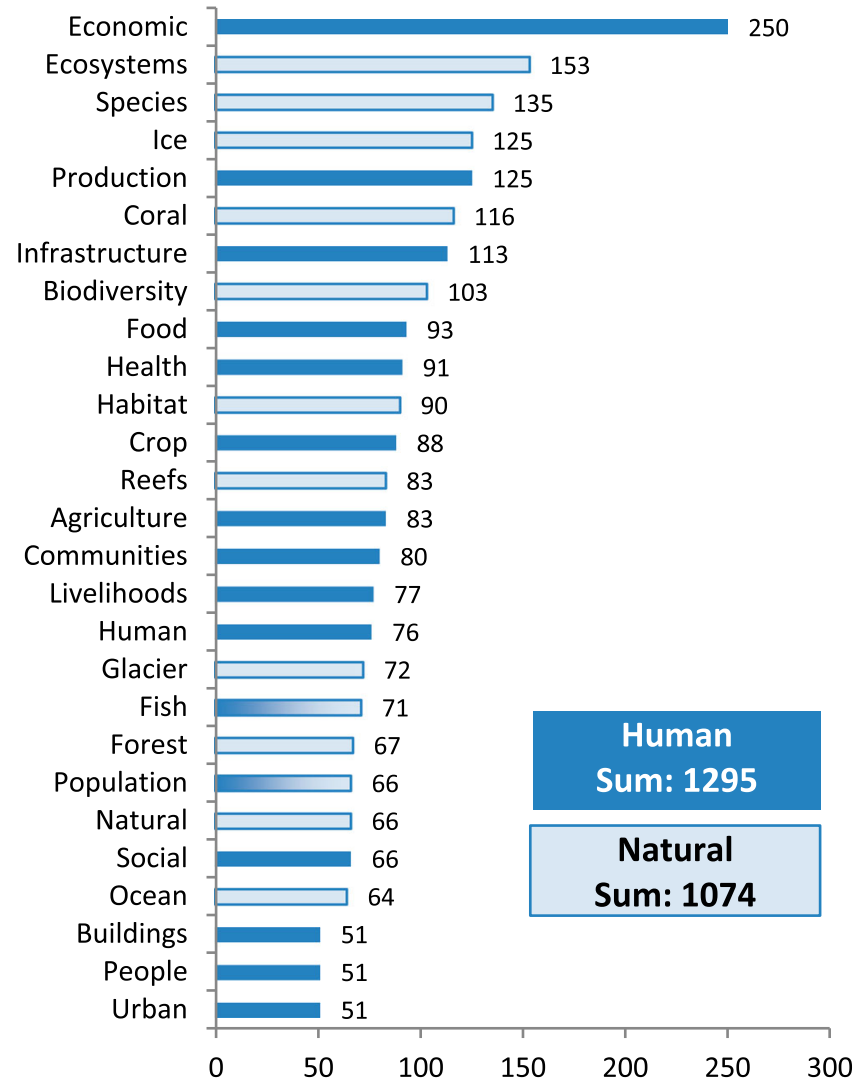

Figure 4. Impacts on natural vs human systems. Source: Authors.

Notes: The threshold for inclusion in the figure was set at 50. 
as ecosystem impacts. ${ }^{2}$ In such instances, the original text was consulted. The words fish and population were used in connection to impacts on human as well as natural systems. Other words, such as production, indigenous and diseases could in theory be used in both realms, but in practice were only used in relation to human impacts.

Overall, WGII AR5 pays a similar level of attention to losses and damages from climate change in human and natural systems (see Figure 4). In natural systems, the report expresses particular concern about losses and damages to ecosystems, species, habitat and biodiversity. Figure 4 also reveals an emphasis on marine and arctic ecosystems and less attention for terrestrial ecosystems. The impacts on human systems discussed in WGIl AR5 primarily involve economic losses and damage to infrastructure. Substantially less attention is given to impacts on food security, health, livelihoods and communities, as is also shown in the next figure (Figure 5).

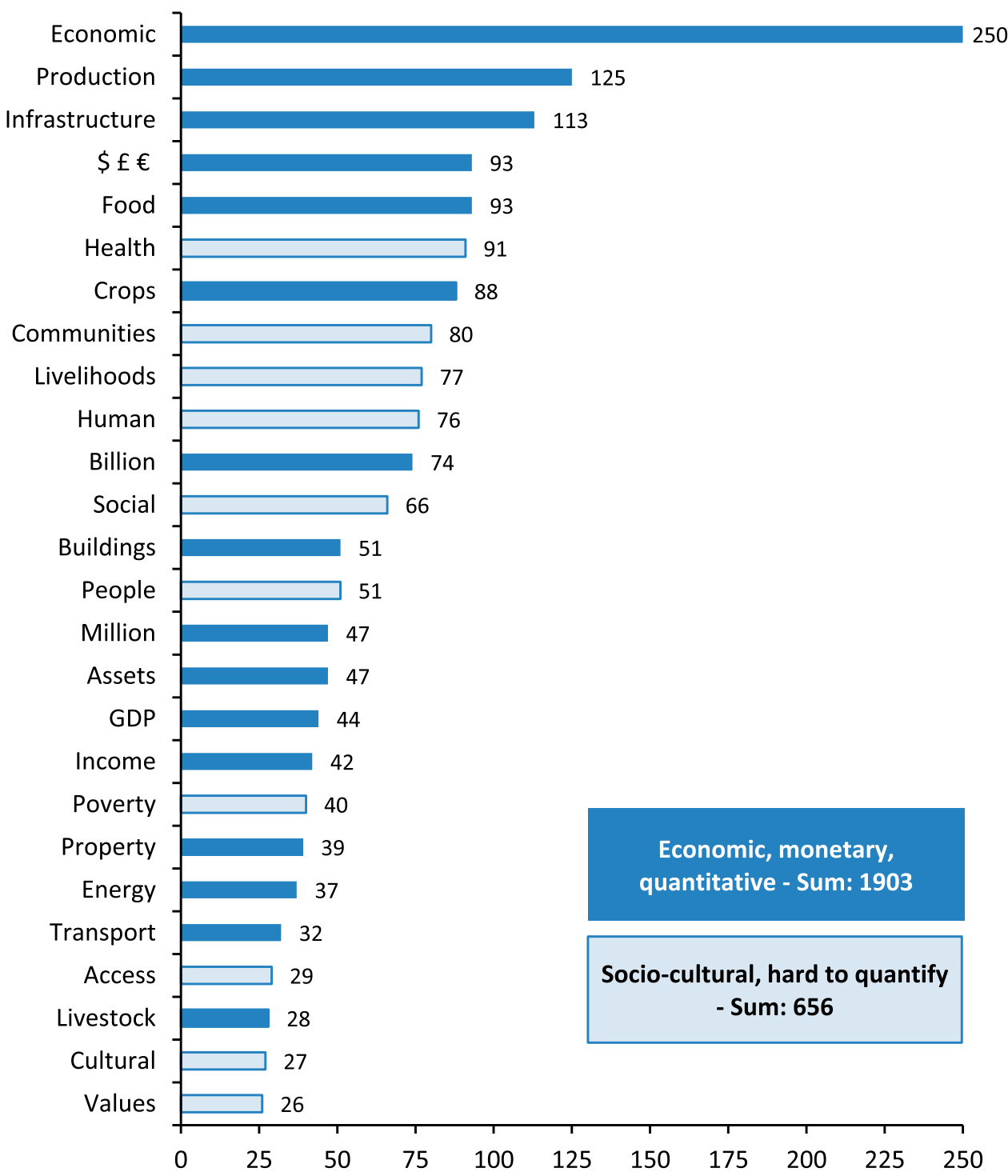

Figure 5. Economic versus socio-cultural losses. Source: Authors.

Note: The threshold for inclusion in the figure was set at 25 . 


\section{Economic and socio-cultural loss and damage}

Figure 5 plots words used in the same sentence with loss/damage that are related to climate impacts on human systems. A distinction is made between economic (the dark blue bars) and socio-cultural (the light blue bars) impacts, or to be more precise, between economic, physical, monetary and quantifiable impacts on the one hand, and socio-cultural, people-centred and hard to quantify impacts on the other. While a distinction is usually made between economic and non-economic losses, we feel that these labels are not fully adequate in this context. Economic losses are defined by the UNFCCC as 'losses of resources, goods and services that are commonly traded in markets.' (UNFCCC, 2013b, p. 3). By contrast, socio-cultural losses are understood in the technical paper as losses to things that are not commonly traded in markets, and therefore challenging to assess.

WGII AR5 reports losses and damages primarily in relation to physical, economic and monetary impacts (the dark blue bars) of climate change and extreme weather events (see Figure 5). On the people-centred side (the light blue bars), food security, health and livelihoods are the key sectors where climate changerelated losses and damages are observed and expected. Climate change-induced food security problems are particularly expected in Sub-Saharan Africa, where temperature increases in some areas may be beyond adaptation limits, and where an increased frequency and intensity of droughts and floods would affect yield levels and post-harvest losses. Expected impacts of climate change on human health would result partly from food insecurity, but also from an increase in vector - and water-borne diseases, associated with global warming.

Below, we have listed a selection of quotes from different chapters that show that WGII AR5, despite its tendency to focus primarily on economic losses, also has some important things to say about non-economic, nonmonetary, social and cultural losses and damages, such as displacement, loss of social identity and loss of damage to cultural heritage:

- SPM, p. 19: 'Disaster loss estimates are lower-bound estimates because many impacts, such as loss of human lives, cultural heritage, and ecosystem services, are difficult to value and monetize, and thus they are poorly reflected in estimates of losses.'

- TS, p.73: 'Loss of land and displacement, for example, on small islands and coastal communities, have well documented negative cultural and well-being impacts.'

- Chapter 5, p.364: 'Without adaptation, hundreds of millions of people will be affected by coastal flooding and will be displaced due to land loss by the year 2100; the majority of those affected are from East, Southeast and South Asia (high confidence).'

- Chapter 16, p.922: 'Strategies such as migration (...) may involve the loss of sense of place and cultural identity, particularly if migration is involuntary.'

- Chapter 29, p. 1639: 'Relocation and displacement are frequently cited as outcomes of sea-level rise, salinization and land loss on islands.'

- Chapter 23, p.5: 'Climate change and sea level rise may damage European cultural heritage, including buildings, local industries, landscapes, archaeological sites, and iconic places [medium confidence].'Geographic regions: continents, countries, regions

\section{Regions}

Whereas vulnerable countries, such as SIDS and LDCs were the main driving force behind the establishment of the WIM (Roberts \& Huq, 2015; Calliari et al., 2019), surprisingly, WGIl AR5 mentions developed countries much more often in relation to loss and damage. The words Europe, Australia, North America and United States cooccur with loss/damage about three times more often than the words Asia, Africa, Latin America and the Pacific (see Figure 6). Similarly, Germany is mentioned in connection to loss/damage more often than the entire Caribbean and almost twice as often as an extremely vulnerable country like Bangladesh. An explanation may be that more research has been done and more robust evidence was available in high-income countries (Hansen \& Cramer, 2015). The composition of IPCC WGIl author teams ${ }^{3}$ might also play a role as authors from developed countries dominate (Ford, Vanderbilt, \& Berrang-Ford, 2012) and may be more familiar with 


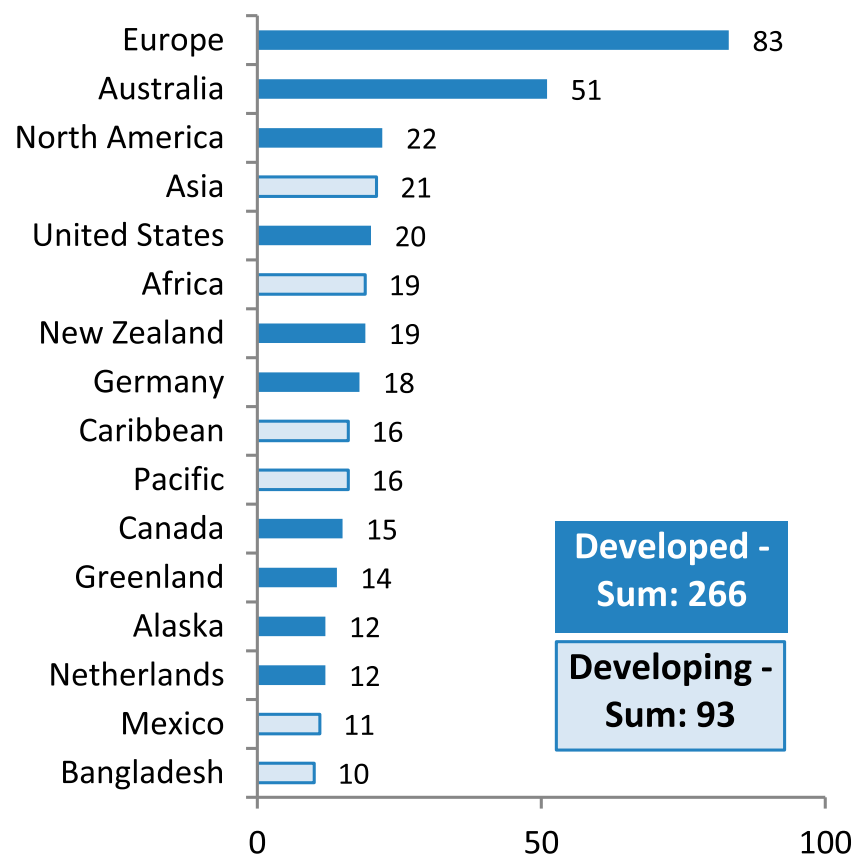

Figure 6. Geographic regions: continents, countries, regions. Source: Authors.

Notes: The threshold for inclusion in the figure was set at 10. Latin America was not mentioned often enough in connection to loss/damage to be included in Figure 6 . The authors acknowledge that Asia includes countries, such as Japan, South Korea and Singapore, that are considered developed countries.

evidence from their own regions. Another reason could be that economic losses, when expressed in monetary terms, tend to be higher in high-income countries. Examples from the United States are Hurricane Katrina and Super-storm Sandy, with an estimated economic damage of US\$100 and 50 billion, respectively (Chapter 5, p. 383).

\section{Conclusion}

This paper used qualitative data analysis software (text mining) to study what WGII AR5 has to say about losses and damages from climate change. The words 'loss' and 'damage' occur over 2,000 times and we assessed which climatic stressors, impact sectors and regions the report primarily associates with losses and damages. In these concluding paragraphs we summarize key findings and highlight the implications for the WIM and the IPCC.

As a concept, 'Loss and Damage' does not feature prominently in WGII AR5, but the SPM and the TS do state with very high confidence that there is a risk of unavoidable losses and damages, despite current and future mitigation and adaptation efforts. Moreover, throughout the 30 chapters of the report, evidence of current losses and damages are presented, and the risks of future losses and damages are assessed. A clear message of the report is that postponing ambitious mitigation action increases the chances of crossing adaptation limits, and could lead to irreversible losses to ecosystems and society, particularly in low-income countries.

The word most often used in connection to losses and damages is risk (386 times) and the chapters in which the words loss and damage appear most frequently are chapter 19 (Emergent risks and key vulnerabilities) and 10 (Key economic sectors and services). This is an indication that the report talks about losses and damages mostly in economic terms and as a future threat. Non-economic losses and damages and the social and cultural dimensions of loss receive less attention. Furthermore, WGII AR5 does not include enough evidence about loss and damage as a reality for vulnerable people today. It is not entirely clear to what extent this is because there is 
a lack of evidence in the academic literature or because of the composition of the IPCC WGIl author teams, which are dominated by economists and others from developed countries (Ford et al., 2012; Carey, James, \& Fuller, 2014). A recommendation of this paper to the IPCC is to include more authors who are familiar with qualitative research on social and cultural dimension of climate change and loss and damage, especially in vulnerable countries. Typically such authors would hail from anthropology, development studies, human geography and psychology. A key resource for the IPCC, and its AR6, could be the expert group on non-economic losses that was established under the current five-year workplan of the WIM (Serdeczny, 2019).

IPCC WGII AR5 discusses losses and damages mostly in relation to floods and other extreme events, such as storms and hurricanes. It has less to say about losses and damages from incremental processes and gradual climatic changes. Here, too, it is not entirely clear to what extent this is because there is a lack of evidence in the academic literature or because IPCC WGIl authors are less familiar with the evidence on losses and damage from incremental and slow-onset processes. While existing disaster loss databases and institutional structures for disaster management can play an important role in assessing and addressing losses and damages (Gall, 2015), the risks of losses and damages from slow-onset processes and gradual climatic changes, and the dangerous interaction between slow-onset processes and sudden-onset events (James et al., 2019), need more attention in IPCC AR6. Just as in the case of non-economic losses, a key resource for the IPCC, and its AR6, could be the technical expert group on slow-onset events that was established under the WIM.

Whereas vulnerable developing countries were the main driving force behind the establishment of the WIM, WGII AR5 mentions developed countries much more often in relation to losses and damages. However, the real losses and damages from climate change in terms of human suffering, disrupted livelihoods and undermined sustainable development pathways are particularly severe in the world's LDCs and SIDS. This is well-recognized under the WIM as its primary focus has from the beginning been on 'developing countries that are particularly vulnerable to the adverse effects of climate change' (UNFCCC, 2013a). The recommendation to the IPCC is to continue and intensify efforts to include more authors from developing countries, and particularly authors from LDCs and SIDS.

The chapters that are most policy-relevant ${ }^{4}$ are also the most silent about loss and damage. This is not surprising because when WGII AR5 was prepared, climate policy focused almost exclusively on mitigation and adaptation. The Paris Agreement has the potential to change that, as it acknowledges that some losses and damages cannot be avoided through mitigation and adaptation policy. Separate policy is needed for such residual loss and damages.

\section{Notes}

1. We analysed the thirty chapters of IPCC WGII AR5 plus the SPM and TS, totalling 2605 pages.

2. The authors acknowledge that impacts on natural systems often affect human systems through loss of ecosystem services (Costanza et al., 1997; Zommers et al., 2016; van der Geest et al., 2019).

3. The IPCC website documents WGIl author team composition. It shows that $41 \%$ come from developing countries or economies in transitions.

4. Chapter 15 (Adaptation planning and implementation), Chapter 14 (Adaptation needs and options) and Chapter 2 (Foundations for decision making).

\section{Disclosure statement}

No potential conflict of interest was reported by the authors.

\section{References}

Botzen, W. W., Bouwer, L. M., Scussolini, P., Kuik, O., Haasnoot, M., Lawrence, J., \& Aerts, J. C. (2019). Integrated disaster risk management and adaptation. In R. Mechler, L. Bouwer, T. Schinko, S. Surminski, \& J. Linnerooth-Bayer (Eds.), Loss and damage from climate change (pp. 287-315). Cham: Springer.

Bouwer, L. M. (2011). Have disaster losses increased due to anthropogenic climate change? Bulletin of the American Meteorological Society, 92(1), 39-46. 
Burton, I. (2009). Climate change and the adaptation deficit. In E. L. F. Schipper, \& I. Burton (Eds.), Earthscan Reader on adaptation to climate change (pp. 89-95). London: Earthscan.

Byrnes, R., \& Surminski, S. (2019). Addressing the impacts of climate change through an effective warsaw international mechanism on loss and damage: Submission to the second review of the warsaw international mechanism on loss and damage under the UNFCCC. London: Grantham Research Institute and London School of Economics and Political Science.

Calliari, E., Surminski, S., \& Mysiak, J. (2019). The politics of (and behind) the UNFCCC's loss and damage mechanism. In R. Mechler, L. Bouwer, T. Schinko, S. Surminski, \& J. Linnerooth-Bayer (Eds.), Loss and damage from climate change (pp. 155-178). Cham: Springer.

Carey, M., James, L. C., \& Fuller, H. A. (2014). A new social contract for the IPCC. Nature Climate Change, 4(12), 1038.

Costanza, R., d'Arge, R., de Groot, R., Farber, S., Grasso, M., Hannon, B., .. van den Belt, M. (1997). The value of the world's ecosystem services and natural capital. Nature, 387, 253-260.

Doelle, M., \& Seck, S. (2019). Loss \& damage from climate change: from concept to remedy? Climate Policy. doi:10.1080/14693062.2019. 1630353

Dow, K., Berkhout, F., Preston, B. L., Klein, R. J., Midgley, G., \& Shaw, M. R. (2013). Limits to adaptation. Nature Climate Change, 3(4), 305-307.

Fankhauser, S., Dietz, S., \& Gradwell, P. (2014). Non-economic losses in the context of the UNFCCC work programme on loss and damage. In Policy paper. Centre for Climate Change Economics and Policy Grantham Research Institute on Climate Change and the Environment. Retrieved from http://www.Ise.ac.uk/Granthamlnstitute/wp-content/uploads/2014/02/Fankhauser-DietzGradwell-Loss-Damage-final.pdf

Ford, J. D., Vanderbilt, W., \& Berrang-Ford, L. (2012). Authorship in IPCC AR5 and its implications for content: Climate change and indigenous populations in WGIl. Climatic Change, 113(2), 201-213.

Gall, M. (2015). The suitability of disaster loss databases to measure loss and damage from climate change. Int J Global Warming, 8(2), 170-190.

Hansen, G., \& Cramer, W. (2015). Global distribution of observed climate change impacts. Nature Climate Change, 5(3), $182-185$.

Huggel, C., Stone, D., Auffhammer, M., \& Hansen, G. (2013). Loss and damage attribution. Nature Climate Change, 3(8), $694-696$.

Hulme, M. (2014). Attributing weather extremes to 'climate change': A review. Progress in Physical Geography: Earth and Environment, 38(August), 499-511.

Huq, S., Roberts, E., \& Fenton, A. (2013). Loss and damage. Nature Climate Change, 3(11), 947-949.

IISD. (2014). Summary of the 10th session of Working Group II of the Intergovernmental Panel on climate change (IPCC) and thirtyeighth session of the IPCC: 25-29 March 2014. Earth Negotiations Bulletin, 12(596), 1-20.

IPCC. (2007). Climate change 2007: Impacts, adaptation and vulnerability. Contribution of working group II to the fourth Assessment report of the intergovernmental panel on climate change. Cambridge: Cambridge University Press.

IPCC. (2014). Climate change 2014: Impacts, adaptation and vulnerability. contribution of working group II to the fifth assessment report of the intergovernmental panel on climate change. Cambridge: Cambridge University Press.

James, R. A., Jones, R. G., Boyd, E., Young, H. R., Otto, F. E., Huggel, C., \& Fuglestvedt, J. S. (2019). Attribution: How is it relevant for loss and damage policy and practice? In R. Mechler, L. Bouwer, T. Schinko, S. Surminski, \& J. Linnerooth-Bayer (Eds.), Loss and damage from climate change (pp. 113-154). Cham: Springer.

James, R., Otto, F., Parker, H., Boyd, E., Cornforth, R., Mitchell, D., \& Allen, M. (2014). Characterizing loss and damage from climate change. Nature Climate Change, 4(11), 938-939.

McNamara, K. E., \& Jackson, G. (2019). Loss and damage: A review of the literature and directions for future research. Wiley Interdisciplinary Reviews: Climate Change, 10(2), e564.

Mechler, R., Calliari, E., Bouwer, L. M., Schinko, T., Surminski, S., Linnerooth-Bayer, J., ... Zommers, Z. (2019). Science for loss and damage. Findings and propositions. In R. Mechler, L. Bouwer, T. Schinko, S. Surminski, \& J. Linnerooth-Bayer (Eds.), Loss and damage from climate change (pp. 3-37). Cham: Springer.

Meinshausen, M., Meinshausen, N., Hare, W., Raper, S. C. B., Frieler, K., Knutti, R., ... Allen, M. R. (2009). Greenhouse-gas emission targets for limiting global warming to $2^{\circ} \mathrm{C}$. Nature, 458, 1158-1162.

Nalau, J., \& Leal Filho, W. (2018). Introduction: Limits to adaptation. In W. Leal Filho \& J. Nalau (Eds.), Limits to climate change adaptation (pp. 1-8). Cham: Springer.

Preston, B., Dow, K., \& Berkhout, F. (2013). The climate adaptation frontier. Sustainability, 5(3), 1011-1035.

Roberts, E., \& Huq, S. (2015). Coming full circle: The history of loss and damage under the UNFCCC. International Journal of Global Warming, 8(2), 141-157.

Roberts, E., \& Pelling, M. (2019). Loss and damage: An opportunity to address the root causes of vulnerability through transformational change? Climate Policy. doi:10.1080/14693062.2019.1680336.

Roberts, E., van der Geest, K., Warner, K., \& Andrei, S. (2014). Loss and damage: When adaptation is not enough. Environmental Development, 11 (July), 219-227.

Schellnhuber, H. J., Hare, B., Serdeczny, O., Adams, S., Coumou, D., Frieler, K., ... Warszawski, L. (2012). Turn down the heat: Why a 4 C warmer world must be avoided. Washington, DC: World Bank.

Serdeczny, O. (2019). Non-economic loss and damage and the Warsaw international mechanism. In R. Mechler, L. Bouwer, T. Schinko, S. Surminski, \& J. Linnerooth-Bayer (Eds.), Loss and damage from climate change (pp. 205-220). Cham: Springer.

Tschakert, P., Ellis, N. R., Anderson, C., Kelly, A., \& Obeng, J. (2019). One thousand ways to experience loss: A systematic analysis of climate-related intangible harm from around the world. Global Environmental Change, 55, 58-72. 
UNFCCC. (2013a). Report of the conference of the parties on its eighteenth session, held in Doha from 26 to 8 December 2012. Addendum. Part two: Action taken by the Conference of the Parties at its eighteenth session. United Nations Framework Convention on Climate Change (UNFCCC). FCCC/CP/2012/8/Add.1.

UNFCCC. (2013b). Non-economic losses in the context of the work programme on loss and damage. UNFCCC Technical Paper TP/ 2013/2.

van der Geest, K., de Sherbinin, A., Kienberger, S., Zommers, Z., Sitati, A., Roberts, E., \& James, R. (2019). The impacts of climate change on ecosystem services and resulting losses and damages to people and society. In R. Mechler, L. Bouwer, T. Schinko, S. Surminski, \& J. Linnerooth-Bayer (Eds.), Loss and damage from climate change (pp. 221-236). Cham: Springer.

van der Geest, K., \& Schindler, M. (2017). Handbook for assessing loss and damage in vulnerable communities. Bonn: UNU-EHS.

van der Geest, K., \& Warner, K. (2015). Loss and damage from climate change: Emerging perspectives. International Journal of Global Warming, 8(2), 133-140.

van Vliet, J., van der Berg, M., Schaeffer, M., van Vuuren, D. P., den Elzen, M., Hof, A. F., ... Meinshausen, M. (2012). Copenhagen accord pledges imply higher costs for staying below $2^{\circ} \mathrm{C}$ warming. Climatic Change, 113(2), 551-561.

Verheyen, R., \& Roderick, P. (2008). Beyond adaptation: The legal duty to pay compensation for climate change damage. Surrey: WWF-UK. Warner, K., \& van der Geest, K. (2013). Loss and damage from climate change: Local-level evidence from nine vulnerable countries. International Journal of Global Warming, 5(4), 367-386.

Warner, K., van der Geest, K., \& Kreft, S. (2013). Pushed to the limits: Evidence of climate change-related loss and damage when people face constraints and limits to adaptation. Report No.11. Bonn: United Nations University Institute for Environment and Human Security (UNU-EHS).

Zommers, Z., van der Geest, K., De Sherbinin, A., Kienberger, S., Roberts, E., Harootunian, G., ... James, R. (2016). Loss and damage: The role of ecosystem services. Nairobi: UNEP. 